\title{
Introduction of Plant and Fungal Genes into Pea (Pisum sativum L.) Hairy Roots Reduces Their Ability to Produce Pisatin and Affects Their Response to a Fungal Pathogen
}

\author{
Qindong Wu and Hans D. VanEtten \\ Division of Plant Pathology and Microbiology, Plant Science Department, University of Arizona, Tucson 85721, U.S.A.
}

Submitted 17 November 2003. Accepted 24 February 2004.

Pisatin is an isoflavonoid phytoalexin synthesized by pea (Pisum sativum L.). Previous studies have identified two enzymes apparently involved in the synthesis of this phytoalexin, isoflavone reductase (IFR), which catalyzes an intermediate step in pisatin biosynthesis, and (+)6a-hydroxymaackiain 3-O-methyltransferase (HMM), an enzyme catalyzing the terminal step. To further evaluate the involvement of these enzymes in pisatin biosynthesis, senseand antisense-oriented cDNAs of Ifr and $\mathrm{Hmm}$ fused to the 35s CaMV promoter, and Agrobacterium rhizogenes, were used to produce transgenic pea hairy root cultures. $P D A$, a gene encoding pisatin demethylating activity (pda) in the pea-pathogenic fungus Nectria haematococca, also was used in an attempt to reduce pisatin levels. Although hairy root tissue with either sense or antisense Ifr cDNA produced less pisatin, the greatest reduction occurred with sense or antisense $\mathrm{Hmm}$ cDNA. The reduced pisatin production in these lines was associated with reduced amounts of $\mathrm{Hmm}$ transcripts, HMM protein, and HMM enzyme activity. Hairy roots containing the $P D A$ gene also produced less pisatin. To evaluate the role of pisatin in disease resistance, the virulence of $N$. haematococca on the transgenic roots that produced the lowest levels of pisatin was tested. Hairy roots expressing antisense $\mathrm{Hmm}$ were more susceptible than the control hairy roots to isolates of $N$. haematococca that are either virulent or nonvirulent on wild-type pea plants. This appears to be the first case of producing transgenic plant tissue with a reduced ability to produce a phytoalexin and demonstrating that such tissue is less resistant to fungal infection: these results support the hypothesis that phytoalexin production is a disease resistance mechanism.

Additional keywords: isoflavonoids, phytoalexin biosynthesis, pisatin demethylase.

Pisatin, the major phytoalexin produced by garden pea (Pisum sativum L.), is a pterocarpan. Pterocarpans are products of the isoflavonoid pathway. The basic pterocarpan carbon skeleton contains rings $\mathrm{ABCD}$, as shown for pisatin in Figure 1, and exist in nature in two stereoisomeric forms, one of which is exemplified by $(+)$ pisatin (Fig. 1). Unlike pea,

Corresponding author: H. D. VanEtten; Fax: 520-621-9290; E-mail: vanetten@ag.arizona.edu

Current address of Q. Wu: Eli Lilly and Company, Indianapolis, IN 46285. most legumes produce the (-) stereoisomer of pterocarpans (Dewick 1988), which have the opposite configuration at asymmetric carbons $6 \mathrm{a}$ and $11 \mathrm{a}$ as that shown for (-) maackiain (Fig. 1). Most models for the biosynthesis of pterocarpans have the reduction of an isoflavone, catalyzed by isoflavone reductase (IFR), as an intermediate step in the biosynthesis of these compounds (Heller and Forkman 1994). The IFR from pea that catalyzes the conversion of 7,2'-dihydroxy$4^{\prime}, 5^{\prime}$-methylenedioxy-isoflavone (DMD) to the isoflavanone sophorol (Fig. 1) was purified (Sun et al. 1991) and a cDNA clone of Ifr subsequently was isolated from pea (Paiva et al. 1994). Interestingly, this IFR, like those from alfalfa (Paiva et al. 1991), chickpea (Schlieper et al. 1990), and soybean (Fischer et al. 1990) converts the symmetric isoflavone to an asymmetric (-) isoflavanone with the configuration at carbon 3 , as shown for (-) sophorol in Figure 1. This is the first step in the pterocarpan pathway in which asymmetry is introduced; therefore, it has long been thought that this step determines the ultimate stereochemistry of the pterocarpans (Dewick 1988). Whereas the subsequent conversion of the (-) isoflavanone to a (-) pterocarpan, as illustrated for (-) maackiain, has been demonstrated for alfalfa (Guo et al. 1994), the manner in which a (+) pterocarpan such as (+) pisatin is synthesized is unknown, and various mechanisms have been proposed (Fig. 1).

Although the step or steps responsible for determining the stereochemistry of (+) pisatin have yet to be described, all the data indicate that the final step in pisatin biosynthesis is the methylation of $(+)$ 6a-hydroxymaackiain at the 3- 0 position (Fig. 1). A methyl transferase, (+) 6a-hydroxymaackiain 3-Omethyltransferase (HMM), has been purified from pea and a cDNA clone encoding HMM was obtained by screening an expression library with polyclonal antibodies against HMM (Preisig et al. 1989; Wu et al. 1997). Both the HMM purified from pea and that expressed from the $\mathrm{Hmm}$ cDNA clone in Escherichia coli have a high degree of preference for (+) 6ahydroxymaackiain (HMK) as the substrate and a low $\mathrm{K}_{\mathrm{m}}$ when this is the substrate for synthesis of $(+)$ pisatin (Preisig et al. 1989; Wu et al. 1997). Finally, the production of HMM transcripts, HMM enzyme activity, and HMM all parallel the production of pisatin in pea tissue induced to synthesize this phytoalexin (Preisig et al. 1989; 1991; Wu et al. 1997).

Although various studies have demonstrated that the production of pisatin normally is correlated with the expression of resistance to disease, separating the cause from the effects in these interactions, as with most studies on phytoalexins, has been difficult to achieve (Kuc 1995). An alternative approach to evaluating the role of pisatin in resistance has been to ask 
whether pisatin detoxification is important for fungal pathogenesis (VanEtten et al. 1989). For the fungus Nectria haematococca mating population VI, detoxification of pisatin is accomplished by demethylation of pisatin at the 3-0 position (Fig. 1) and is catalyzed by pisatin demethylase (pda), a cytochrome P450 (Maloney and VanEtten 1994). Mutation of the gene (PDA) encoding this activity in $N$. haematococca by transformation-mediated gene disruption has been accomplished and the resulting mutants shown to have reduced virulence on pea (Wasmann and VanEtten 1996). These results imply that pisatin production is one of the disease resistance mechanisms in pea. However, the availability of $P$. sativum plants which lack the ability to produce pisatin would provide a direct way to evaluate the relative role this phytoalexin plays in interactions with other potential pathogens as well as with beneficial microbes.

The purpose of this study was to determine if sense or antisense constructs of Ifr, Hmm, and PDA genes could be used to produce transgenic pea tissue with a reduced ability to synthesize or accumulate pisatin. Because of the ease of use and the short time required to produce hairy root cultures, this experimental system was used to produce transgenic pea tissue expressing these genes instead of intact plants. In addition, because $N$. haematococca is a root rot pathogen, an effect on the susceptibility of pea tissues that accumulate less pisatin could be tested directly by determining the relative susceptibility of transgenic roots with different abilities to accumulate pisatin.

\section{RESULTS}

\section{Pisatin biosynthesis in hairy roots.}

The Agrobacterium rhizogenes-mediated transformation method, as described by Wen and associates (1999), was used to create transformed pea roots ("hairy roots") from stem tissue of pea. Hairy roots transformed with the Ri plasmid of $A$. rhizogenes ( $\mathrm{Ri}$ plasmid [Rip] controls) and the $\mathrm{Ri}$ plasmid along with the binary vector lacking transgene inserts (Ri plasmid plus binary vector [Ripbv] control) contained small amounts of pisatin (approximately $7 \mu \mathrm{g} / \mathrm{g}$ dry wt) and had a constitutive level of HMM activity (approximately 2 pkat $/ \mathrm{mg}$ of protein), but treatment with $\mathrm{CuCl}_{2}$ elicited increased levels of HMM activity and pisatin (Table 1). The optimal concentration of $\mathrm{CuCl}_{2}(0.5 \mathrm{mM})$ for eliciting pisatin production was lower than the optimal concentration $(1.0 \mathrm{mM})$ for roots from normal plants (data not shown). Pisatin was produced in the hairy root cultures and the roots responded to an elicitor by producing higher levels of the phytoalexin; therefore, the hairy roots grown in culture were judged to be suitable for evaluating the effects of introduced genes on pisatin biosynthesis.

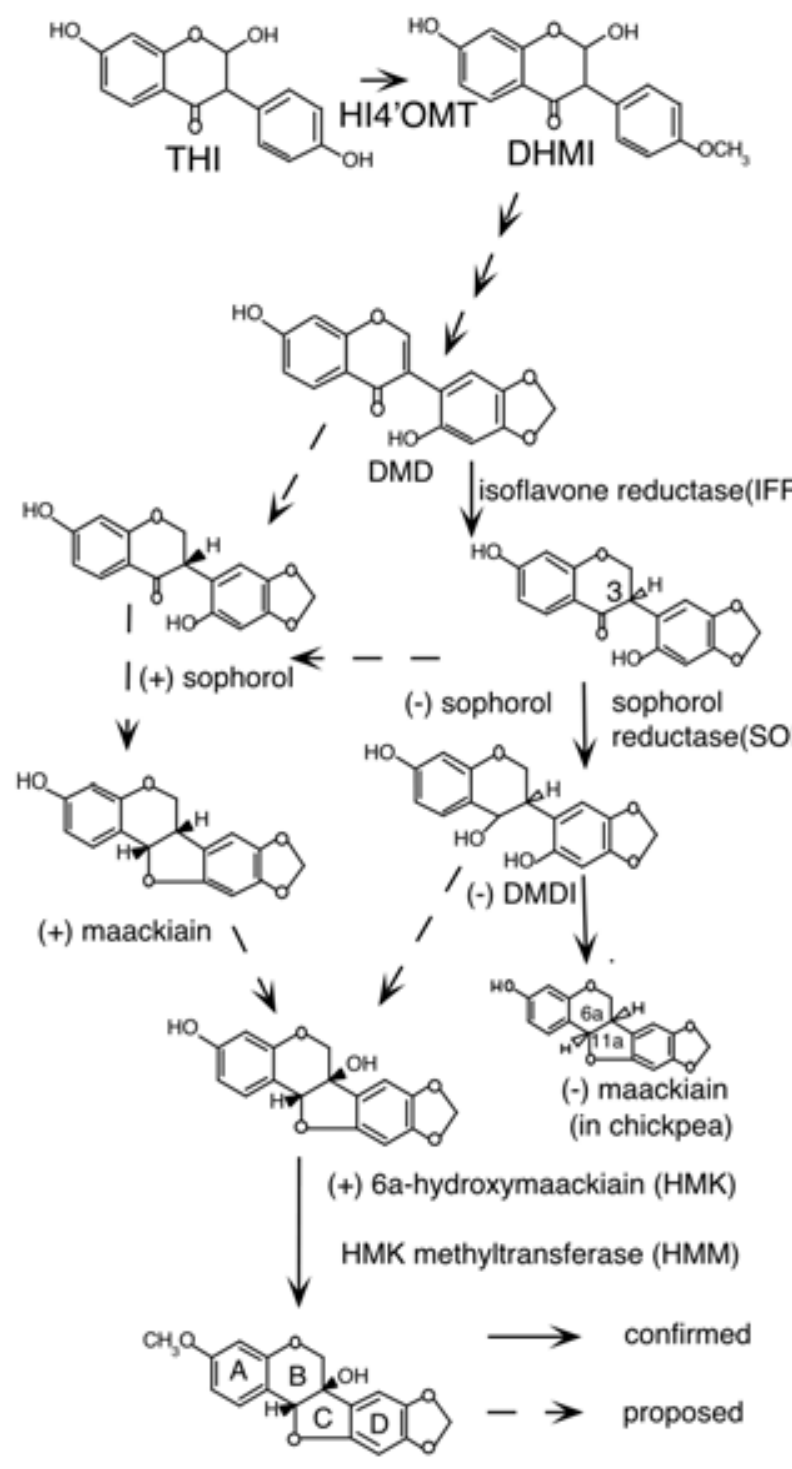

(+) pisatin (pea)

Fig. 1. Proposed early and late steps in the biosynthesis of (+) pisatin and () maackiain. The dashed arrows represent steps proposed by Banks and Dewick (1982, 1983) or DiCenzo (1998) and the solid arrows denote reactions for which the catalyzing enzymes have been cloned. THI $=2,7,4^{\prime}-$ trihydrioxyisoflavanone, DHMI $=2,7$, -dihydrioxy-4'-methoxyisoflavanone, DMD $=7,2^{\prime}$-dihydroxy-4',5'-methylenedioxy-isoflavone, DMDI $=7,2^{\prime}$ dihydroxy-4',5'-methylenedioxyisoflavanol, HI4'OMT = SAM: 2,7, $4^{\prime}-$ trihydrioxyisoflavanone $4^{\prime}-O$-methyltransferase.

Table 1. Pisatin concentration and (+) 6a-hydroxymaackiain 3-O-methyltransferase (HMM) activity in $\mathrm{CuCl}_{2}$-treated transgenic hairy roots ${ }^{\mathrm{a}}$

\begin{tabular}{|c|c|c|c|}
\hline Hairy root clone & Gene, orientation ${ }^{b}$ & Pisatin $(\mu \mathrm{g} / \mathrm{g} \text { of dry wt })^{\mathrm{c}}$ & HMM activity (pKat/mg protein) \\
\hline Ri plasmid control & Ri plasmid alone & $27.8 \pm 4.1$ & $12.3 \pm 5.7$ \\
\hline Ri plasmid and binary vector control & Ri plasmid and binary vector & $25.0 \pm 4.9$ & $13.1 \pm 6.4$ \\
\hline I8-7 & Antisense $I F R$ & $18.6 \pm 3.3$ & NA \\
\hline $18-3$ & Antisense $I F R$ & $16.8 \pm 1.3$ & NA \\
\hline I17-6 & Sense $I F R$ & $18.4 \pm 0.7$ & NA \\
\hline I17-3 & Sense $I F R$ & $17.4 \pm 0.1$ & NA \\
\hline $39-10$ & Sense $P D A$ & $15.6 \pm 3.4$ & NA \\
\hline $39-3$ & Sense $P D A$ & $11.9 \pm 3.9$ & NA \\
\hline $\mathrm{AsH} 2$ & Antisense $H M M$ & $9.7 \pm 1.9$ & $0.7 \pm 0.7$ \\
\hline AsH4 & Antisense $H M M$ & $15.9 \pm 4.3$ & $2.4 \pm 1.8$ \\
\hline H4-7 & Sense $H M M$ & $14.7 \pm 4.6$ & $2.8 \pm 0.5$ \\
\hline H4-6 & Sense $H M M$ & $9.7 \pm 2.2$ & NA \\
\hline
\end{tabular}

${ }^{\mathrm{a}}$ The double CaMV $35 \mathrm{~S}$ promoter was used to drive the expression of all the genes.

${ }^{\mathrm{b}}$ IFR, isoflavone reductase; PDA, pisatin demethylating activity; HMM, (+)6a-hydroxymaackiain 3-O-methyltransferase.

${ }^{c}$ Values are the averages and standard deviations of four independent measurements.

${ }^{\mathrm{d}}$ Values are the averages and standard deviations of six independent measurements; NA $=$ not analyzed 
Transformation of pea hairy roots with Ifr, $\mathrm{Hmm}$, and $P D A$.

The initial experiments utilized binary vectors containing either a single CaMV 35S promoter fused to a partial fragment of the Hmm gene or a single CaMV $35 \mathrm{~S}$ promoter fused to a full-length copy of the Ifr gene. As with all constructs, approximately 10 hairy root cultures which contained the binary vector (i.e., were positive for the drug resistance marker carried by the binary vector) were selected and assayed for pisatin content. Because only two of these cultures (those that contained the fulllength copy of Ifr) produced pisatin amounts (approximately 19 $\mu \mathrm{g} / \mathrm{g}$ dry wt) lower than the controls, future efforts utilized vectors that contained a double copy of the CaMV $35 \mathrm{~S}$ promoter. Full-length sense and antisense constructs of Ifr and Hmm fused to the double CaMV 35S promoter and a full-length sense construct of $P D A$ fused to the double CaMV $35 \mathrm{~S}$ promoter were

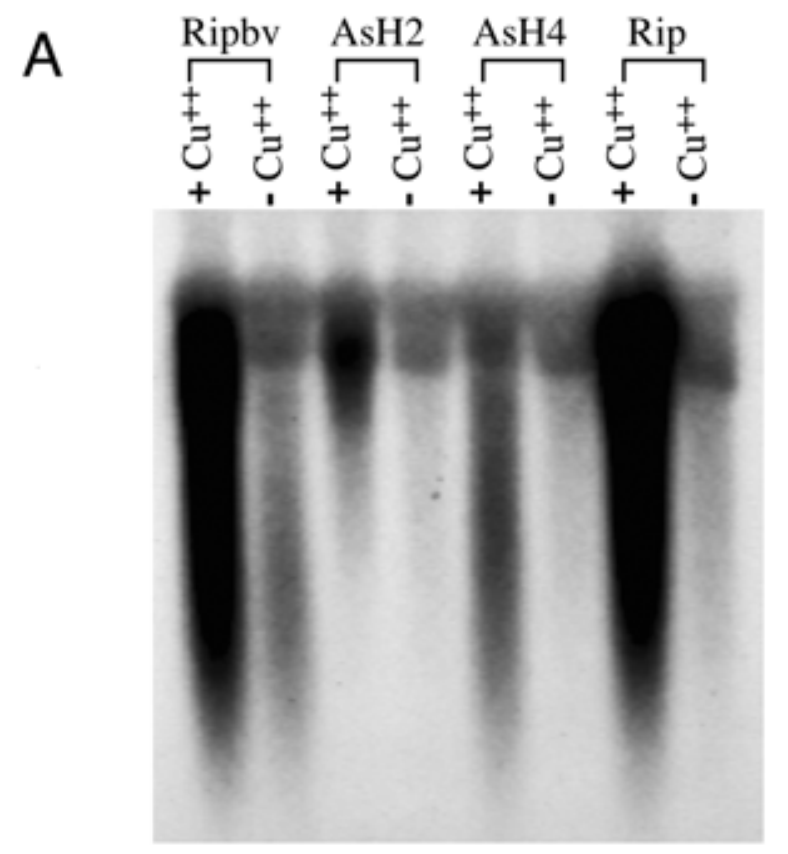

B

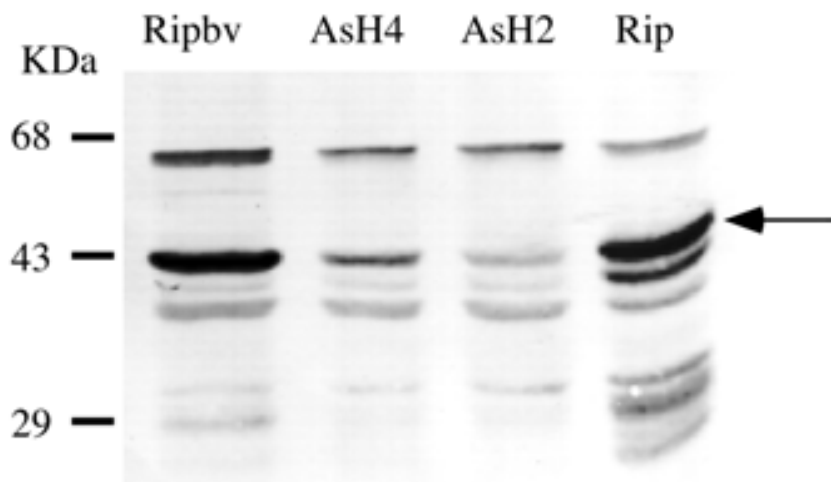

Fig. 2. A, Northern analysis of (+)6a-hydroxymaackiain 3-O-methyltransferase $(\mathrm{hmm})$ transcripts from hairy root cultures. The roots were treated for $1 \mathrm{~h}$ with $0.5 \mathrm{mM} \mathrm{CuCl}_{2}$, incubated for $16 \mathrm{~h}$ without $\mathrm{CuCl}_{2}$, and harvested. Controls received no $\mathrm{CuCl}_{2}$. Total RNA (15 $\left.\mu \mathrm{g} / \mathrm{lane}\right)$ from hairy root cultures containing the Ri plasmid and the binary vector (Ripbv), the Ri plasmid (Rip), and the antisense constructs (AsH2 and ASH4) was analyzed. The probe was antisense ${ }^{32} \mathrm{P}$-RNA transcribed using the $\mathrm{Hmm}$ gene in pHMM1 as a template. B, Western analysis for HMM. Protein extracts (45 $\mu \mathrm{g} /$ lane from hairy roots treated as in $\mathbf{A}$ ) were subjected to western analysis using a polyclonal antibody to HMM. The position of HMM is denoted with an arrow. placed in the binary vector and used to induce the formation of hairy roots. All of these constructs resulted in some hairy root cultures that had a reduced concentration of pisatin. The cultures with the lowest levels of pisatin were those containing $H m m$ or PDA and are shown in Table 1. The PDA-transformed hairy roots initially had pisatin demethylating activity (22 to 46 pmole demethylated/mg fresh wt/h), but this activity was not detected after 2 months in culture. The level of pisatin produced by the $P D A$-transformed cultures also returned to that of the controls, suggesting the that fungal gene was silenced or lost.

The greatest reduction in the level of pisatin was obtained with roots transformed with the sense- or antisense-Hmm constructs; therefore, the level of HMM activity in three of these was measured. The activity was significantly lower than that of the control hairy root cultures (Table 1). Additional analyses were performed on the two antisense-Hmm hairy roots cultures (AsH2 and AsH4).

\section{Characterization of $\mathrm{AsH} 2$ and AsH4.}

Primers made to a region of the CaMV $35 \mathrm{~S}$ promoter and an internal region of the $\mathrm{Hmm}$ gene were used to amplify genomic DNA by polymerase chain reaction (PCR). A PCR product of the predicted size was detected when DNA from $\mathrm{AsH} 2$ and AsH4 hairy roots was used as the template, whereas the fragment was not detected when DNA from the controls was used as the template (data not shown). These results are consistent with the presence of antisense- $\mathrm{Hmm}$ construct in $\mathrm{AsH} 2$ and AsH4. As previously shown (Table 1), treatment of AsH2 and $\mathrm{AsH} 4$ with $\mathrm{CuCl}_{2}$ elicited less pisatin and lower HMM activity than was elicited in the Rip and Ripbv hairy root controls. The diminished response to this elicitor relative to the controls also was reflected in reduced levels of $\mathrm{Hmm}$ transcript as measured by Northern analysis (Fig. 2A) and in less HMM protein as determined by Western analysis (Fig. 2B).

\section{Response of AsH2 and AsH4 hairy roots to $N$. haematococca.}

Hairy roots have been used previously to evaluate the responses of roots to root-associated microorganisms, particularly nitrogen-fixing bacteria and mycorrhizal fungi (Balaji et al. 1995; Benhamou and Garand 2001; Boisson-Dernier et al. 2001; vanEijsden et al. 1995). One technical difficulty in using hairy root cultures with a fungus like $N$. haematococca, which is not an obligate parasite, is that this fungus grows readily on the culture medium supporting the roots. In order to force $N$. haematococca into a parasitic growth phase and to minimize its growth on the root culture medium, isolates of $N$. haematococca which were auxotrophic for an amino acid (methionine [met]) not in the growth medium and had different levels of virulence were constructed. Two met isolates (364-23 and 364$81)$ that were highly virulent on wild-type plants in our standard assays, and two that were not (359-14 and 361-12), were produced and used to inoculate control hairy root cultures (Rip and Ripbv), AsH2 and AsH4. The amount of necrosis that developed 15 days after inoculation was rated on a scale of 0 (no necrosis) to 5 (all of the roots necrotic) and an analysis of variance was carried out. The average of the ratings $(2.5 \pm 0.6)$ of the control hairy root cultures (Rip and Ripbv) inoculated with the four isolates was significantly $(P<.0001)$ lower than the average $(4.0 \pm 0.2)$ for $\mathrm{AsH} 2$ and $\mathrm{AsH} 4$. There was no significant difference between the virulent and nonvirulent isolates on the control roots $(3.0 \pm 0.6$ versus $2.4 \pm 0.7)$ or the antisense-Hmm hairy root cultures $(4.1 \pm 0.2$ versus $4.0 \pm 0.3)$. Examples of the responses of the roots are shown in Figure 3. The significantly increased susceptibility of the antisense$\mathrm{Hmm}$ hairy root cultures was evident throughout the duration of the assay. 
Fifteen days after inoculation, the cultures were analyzed for pisatin content and HMM activity. All of the control roots inoculated with $364-23$ or $361-12$ had higher HMM activity (Fig. 4A) and a higher pisatin content (Fig. 4B) than the antisense-containing roots and the uninoculated roots. Hairy roots inoculated with 364-81 and 359-14 showed the same levels and pattern of pisatin content and HMM activity as roots inoculated with 364-23 or 361-12 (data not shown).

\section{DISCUSSION}

All three of the genes used to make transgenic pea roots reduced the amount of pisatin that accumulated after treatment with $\mathrm{CuCl}_{2}$ or infection with $N$. haematococca (Table 1; Fig. 4). The hairy root cultures transformed with antisense- $\mathrm{Hmm}$ demonstrated less HMM enzyme activity and protein and fewer Hmm transcripts (Figs. 2 and 4); therefore, the reduction in pisatin production presumably was due to a decrease in the number of $\mathrm{Hmm}$ transcripts present after elicitation. Although the reason for a decrease in pisatin accumulation in hairy root cultures with a sense or antisense Ifr was not examined, it would be expected that a similar mechanism would be operating for this plant gene. In contrast, the presence of pda activity in hairy roots containing the $N$. haematococca PDA gene suggests that decreased accumulation of pisatin was due to the degradation of pisatin as it was being synthesized.
In all cases, the effect of the introduced genes was lost after repeated transfers of the cultured roots (unpublished results). Nevertheless, the reduction in pisatin accumulation was persistent enough in the antisense $\mathrm{Hmm}$ roots to evaluate the effect of this reduced capacity to produce pisatin on the susceptibility of the roots to $N$. haematococca. These roots became more susceptible than the control hairy roots to isolates normally virulent or nonvirulent on wild-type plants (Fig. 3). One unexpected result was that the control roots (Rip and Ripbv) (Fig. 3) were not more susceptible to the isolates which normally are highly virulent on the roots of intact plants than they were to the nonvirulent isolates. In spite of this unexpected result, the data are consistent with pisatin playing a role in the defense of peas against microbial infection.

The production of intact plants that are deficient in phytoalexin production would allow for an evaluation of the role of these plant metabolites in more natural situations than can be done with cultured transgenic organs. Mutational approaches have been used to produce Arabidopsis mutants that are deficient in the ability to produce the Arabidopsis phytoalexin camalexin and have been of great use in evaluating the role of camalexin in disease resistance (Thomma et al. 1999). In plant species where some phytoalexin biosynthetic genes are known, those genes can be targeted for silencing as a means to reduce phytoalexin production, and the hairy roots system provides a convenient and rapid means to determine if a particular

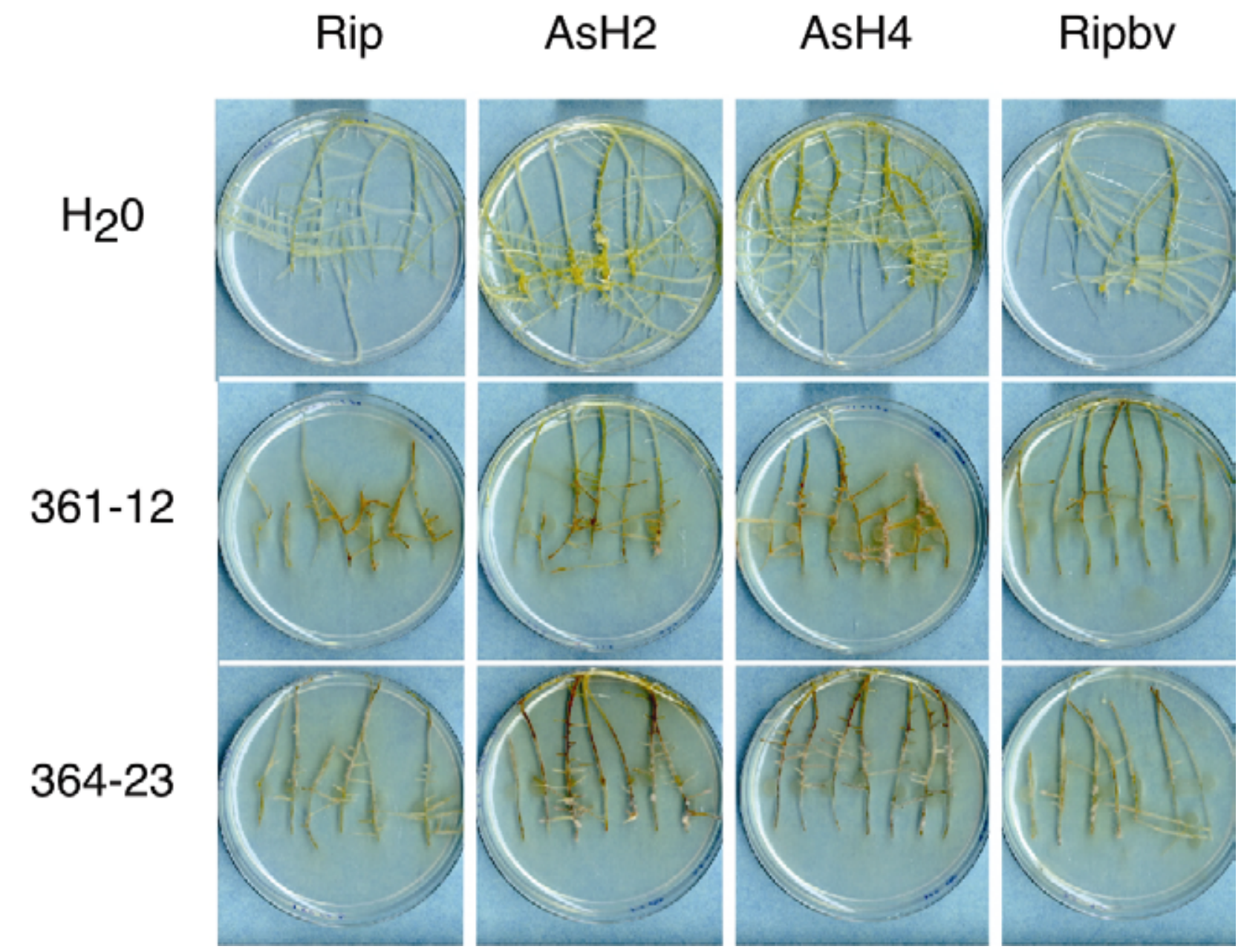

Fig. 3. Symptom development on pea hairy roots, which differ in their capacity to produce pisatin, after inoculation with isolates $364-23$ and $361-12$ of Nectria haematococca. The roots were inoculated with $10 \mathrm{ml}$ of a spore suspension $\left(7 \times 10^{6} / \mathrm{ml}^{2}\right)$ of the methionine (met $\left.{ }^{-}\right)$isolate $361-12$ with low virulence or the highly virulent met isolate $364-23$ or with $10 \mathrm{ml} \mathrm{of} \mathrm{H}_{2} \mathrm{O}$. The plates were incubated at $24^{\circ} \mathrm{C}$ for 15 days and photographed. Control hairy roots contained the Ri plasmid (Rip) or the Ri plasmid and the binary vector (Ripbv). Hairy root cultures AsH2 and AsH4 contained an antisense construct of Hmm. 
targeting strategy is likely to work in intact plants. In addition to the results presented here, Colliver and associates (1997) demonstrated that antisense constructs, in this case of chalcone synthase, can be used to reduce the amount of phytoalexin produced in hairy root cultures of Lotus corniculatus L. Thus, there are several genes involved in phytoalexin biosynthesis in which there is preliminary data to suggest that they could be used to produce intact transgenic plants with a decreased ability to produce phytoalexin.

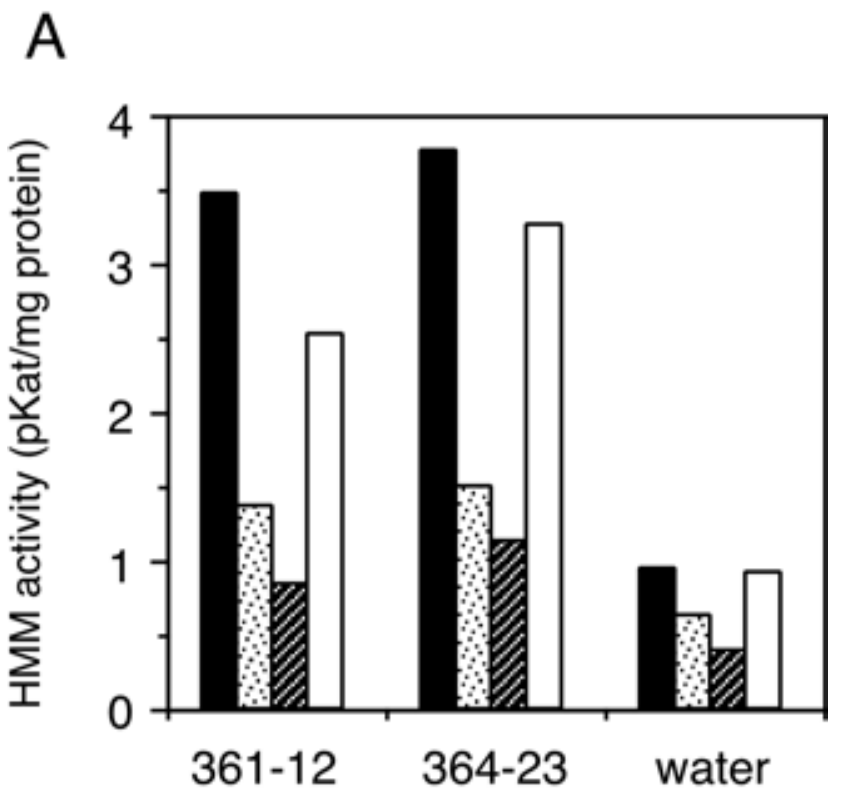

B

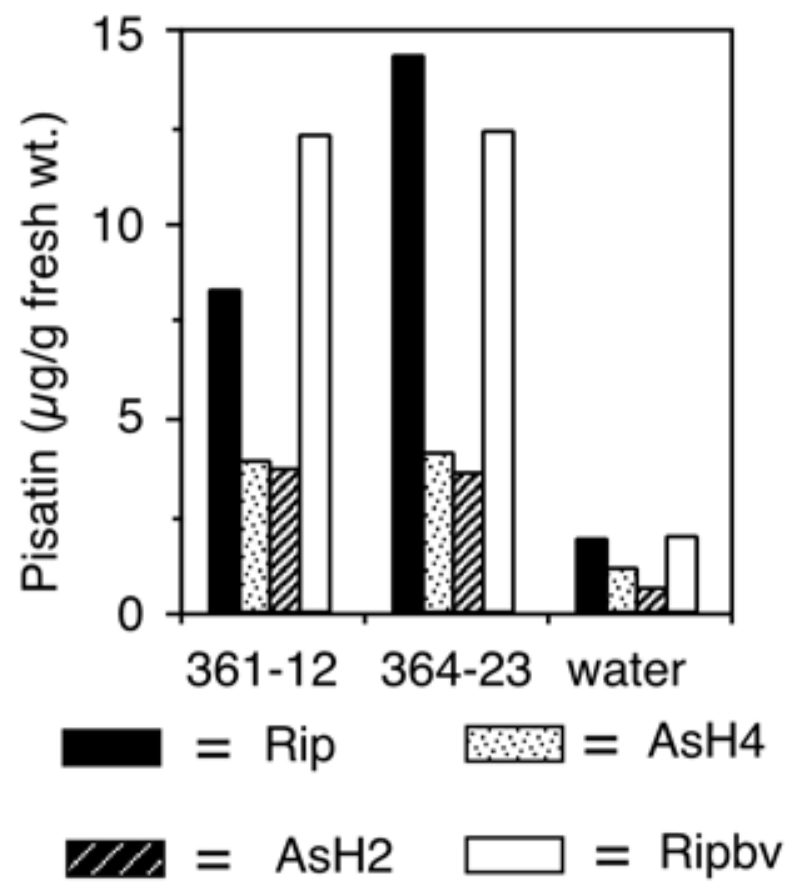

Fig. 4. A, (+)6a-Hydroxymaackiain 3-O-methyltransferase (HMM) activity and $\mathbf{B}$, pisatin levels in hairy roots cultures infected with Nectria haematococca isolates 364-23 and 361-12. The roots were inoculated with $10 \mathrm{ml}$ of a spore suspension $\left(7 \times 10^{6} / \mathrm{ml}\right)$ of the methionine $\left(\mathrm{met}^{-}\right)$ isolate 361-12 with low virulence or the highly virulent met $^{-}$isolate 36423 or with $10 \mathrm{ml}$ of $\mathrm{H}_{2} \mathrm{O}$. The plates were incubated at $24^{\circ} \mathrm{C}$ for 15 days and photographed. Roots were assayed 15 days after inoculation and are from a single measurement.
Another approach which has been used to reduce the amount of a plant metabolite in transgenic plants is the introduction of a microbial gene to degrade a specific plant metabolite. The introduction of the bacteria gene $N a h G$ to degrade salicylic acid has been of great utility for evaluating the role of this plant metabolite in plants (Gaffney et al. 1993). Two fungal genes that detoxify phytoalexins have been introduced into plants for the purpose of reducing the level of phytoalexin produced. The introduction of one of these is described in this article. Another $N$. haematococca gene (Makl) that detoxifies the phytoalexins maackiain and medicarpin has been shown to produce this detoxifying enzyme in transgenic Makl tobacco plants (Mundodi et al. 2001). Thus, Makl is a likely candidate gene to reduce the level of medicarpin and maackiain in plants which normally produce these phytoalexins. The availability of fungal genes that detoxify phytoalexins and plant genes involved in the biosynthesis of phytoalexins in concert with the advances in RNA interference technology should give ample means to produce transgenic plants which lack the ability to accumulate their normal complement of phytoalexins.

The reduction of pisatin accumulation in transgenic pea roots containing the sense and antisense Ifr and Hmm constructs corroborates earlier results placing Ifr and Hmm in the pathway for pisatin synthesis. Only one IFR enzyme and gene have been found in pea (Paiva et al. 1994); therefore, the stereochemistry of (+) pisatin must be established after the reduction catalyzed by Ifr (Fig. 1) or by another means. The decreased level of pisatin accumulating in the transgenic tissue containing the sense and antisense Hmm constructs is consistent with $\mathrm{Hmm}$ catalyzing the terminal step in pisatin biosynthesis. However, after this current study was completed, Akashi and associates (2003) reported the isolation and characterization of a methyltransferase, SAM, 2,7,4'-trihydrioxyisoflavanone 4'- $O$-methyltransferase (HI4'OMT), that methylates $2,7,4^{\prime}$-trihydrioxyisoflavanone (THI) to 2,7,-dihydrioxy-4'-methoxyisoflavanone (DHMI) (Fig. 1) from Glycyrrhiza echinata. The methyltransferase isolated by Akashi and associates (2003) is 83\% identical to $\mathrm{Hmm}$ and is required for synthesis of all isoflavonoids. Thus, a decrease in HI4'OMT activity also would be expected to cause a reduction in the accumulation of pisatin in pea. Interestingly, pea appears to have two copies of the Hmm gene (Wu et al. 1997). In addition, the polyclonal antibodies to HMM reacted with several polypeptides, some of which were present in reduced amounts in the transgenic roots containing the antisense $\mathrm{Hmm}$ construct. Preliminary attempts to detect HMK in the transgenic tissue were unsuccessful (unpublished results). The apparent lack of accumulation of HMK would be expected in the antisense Hmm roots if the pathway were silenced upstream of the terminal step. Further studies clearly are needed to elucidate the terminal steps in the synthesis of $(+)$ pisatin.

\section{MATERIALS AND METHODS}

\section{Plant materials: vector construction and plant transformation.}

A 1,337-bp EcoRI/XhoI fragment from plasmid pHMM1, which contains the complete open reading frame and 13 and 240 nucleotides of the $5^{\prime}$ and $3^{\prime}$ untranslated region of the pea $\mathrm{Hmm}$ (Wu et al. 1997), was cloned in either the sense or antisense orientation relative to the CaMV $35 \mathrm{~S}$ promoter in pJIT117V2 (Grebenok et al. 1997). The resulting plasmids were named pDS35H5 (antisense Hmm) or pDS35H4 (sense $H \mathrm{~mm}$ ). The 2.76-kb fragments which contained the CaMV $35 \mathrm{~S}$ promoter, the $\mathrm{Hmm}$ fragment in sense and antisense orientation, and the CaMV $35 \mathrm{~S}$ polyadenylation signal subsequently were cloned separately into the plant binary vector Bin 19 (Frisch et al. 1995). The resulting binary vectors, 
pDS35H5-14 (sense) or pDS35H4-22 (antisense), were transferred from E. coli to Agrobacterium rhizogenes R1000 by triparental mating.

The sense Ifr (pDS53I17) or antisense Ifr (pDS35I8) vectors containing $957 \mathrm{bp}$ of the open reading frame of Ifr were constructed in a manner similar to that described for Hmm constructs, except that the Ifr gene fragment was excised from pIFR11 (Pavia et al. 1994).

The PDA gene was obtained by screening a cDNA library made from pea tissue infected with $N$. haematococca (Han et al. 2001), using a 1.4-kb SstI fragment from pSacB (Maloney and VanEtten 1994) that contains a portion of the genomic $P D A$ gene. A cDNA clone (PDAcDNA52) that contained the entire open reading frame of $P D A$ was isolated. The 1,734-bp DNA fragment from PDAcDNA52 containing the entire amino acid coding region of the PDA gene subsequently was subcloned into pJIT117V2 (Grebenok et al. 1997) to create pDSPDA39. The binary vector pDSPDA39-15 was constructed as described for $\mathrm{Hmm}$.

Transgeneic hairy root cultures of pea were made as described by Wen and associates (1999). In the case of antisense $\mathrm{Hmm}$-transformed hairy roots, the presence of T-DNA in kanamycin-resistant hairy roots was confirmed by PCR amplification. Genomic DNA was isolated from kanamycin-resistant hairy roots as described by $\mathrm{Wu}$ and associates (1997) and amplified using primer 161 (corresponding to the $5^{\prime}$ region of the $\mathrm{Hmm}$ gene, GGAACTAGGCATAGCTGATG) (Wu et al. 1997) and primerD35S (corresponding to the $5^{\prime}$ region of CaMV double $35 \mathrm{~S}$ promoter, AGACCCTTCCTCTATATAAG) (Franck et al. 1980).

As soon as hairy roots were confirmed to contain the antisense $\mathrm{Hmm}$ construct, they were grown on Gamborg's B5 medium without carbenicillin and transferred approximately every 25 days. After two transfers, the hairy roots were treated and analyzed.

\section{Production of methione auxotrophs \\ of $N$. haematococca with low and high virulence on pea.}

Isolates were cultured and crossed, and random ascospores isolated, as previously described (Tegtmeier and VanEtten 1982). Their pda phenotypes and virulence on pea were scored as previously reported (Mackintosh et al. 1989; VanEtten 1978). Methionine auxotrophs were created by UV irradiation and the trait subsequently was crossed into ascospore isolates 47-2 and 110-3 (Tegtmeier 1981; unpublished data) and then 171-3 (unpublished data). Both 110-3 and 171-3 were moderately virulent on pea and subsequent crosses were required to obtain both high- and low-virulence met ${ }^{-}$isolates. Previous studies had shown that virulence is linked to pda; therefore, the progeny were screened first for this phenotype and for met in order to reduce the number of progeny to be assayed for virulence. Isolate 77-1-2 (met $\left.{ }^{+}, \mathrm{pda}^{+}\right)$from Kistler (1983) was crossed (cross 359) with 47-2 (met ${ }^{-}, \mathrm{pda}^{-}$) and with 171-3 $\left(\mathrm{met}^{-}, \mathrm{pda}^{+}\right)$(cross 361). Isolates 359-14 ( $\left.\mathrm{met}^{-}, \mathrm{pda}^{-}\right)$and (361-12 (met $\left.{ }^{-}, \mathrm{pda}^{-}\right)$were selected from the progeny. Isolates 359-14 and 361-12 are nonvirulent on pea plants in the "pot assay" ( 0 ratings for both) and in the "stem assay" (average lesion size $=2$ and $4 \mathrm{~mm}$, respectively). Isolate 94-1-6 $\left(\mathrm{met}^{+}\right.$, $\mathrm{pda}^{+}$) from Kistler (1983) was crossed with 171-3 (cross 364) and progeny isolates 364-23 (met $\left.{ }^{-}, \mathrm{Pda}^{+}\right)$and 364-81(met ${ }^{-}$, $\mathrm{Pda}^{+}$) were selected. Isolates 364-23 and 364-81 are virulent on pea plants in the pot assay (7 and 8 rating, respectively) and in the stem assay (average lesion size $=20 \mathrm{~mm}$ for both).

\section{Virulence assay.}

Seven hairy roots approximately $10 \mathrm{~mm}$ in length were transferred to a plate containing Gamborg's B5 agar medium and grown in the dark at $24^{\circ} \mathrm{C}$ for 7 days. A spore suspension $\left(10 \mathrm{ml} ; 7 \times 10^{6}\right.$ spores $/ \mathrm{ml}$ of sterile water), prepared from 7 day-old cultures, was deposited on the middle of each hairy root. The control hairy roots were treated with water. The hairy roots were incubated in the dark at $24^{\circ} \mathrm{C}$ for 15 days, then photographed (Fig. 3). A coded picture of each hairy root culture was scored by four individuals for the degree of necrosis using a scale of 0 (no necrosis on any root) to 5 (complete necrosis on all roots). The values from two experiments with all four isolates were used to tabulate the average values and to run an analysis of variance.

After the hairy roots were photographed, the infected roots were harvested, frozen by immersion in liquid nitrogen, and stored until assayed for the amount of pisatin and HMM activity.

\section{Enzyme assay and Western analysis.}

The hairy roots $(3 \mathrm{~g})$ treated with $\mathrm{CuCl}_{2}$ were ground into a fine powder in liquid nitrogen with a mortar and pestle. Four $\mathrm{ml}$ of $0.1 \mathrm{M} \mathrm{K}_{2} \mathrm{PHO}_{4}$ buffer $(\mathrm{pH} \mathrm{7})$ containing $5 \mathrm{mM}$ dithiothreitol, $5 \mathrm{mM}$ EDTA, $14 \mathrm{mM}$ 2-mercaptoethanol, and $0.4 \mathrm{M}$ sucrose were added to the powdered roots, mixed, and centrifuged at $17,000 \times g$ for $30 \mathrm{~min}$. The supernatant was concentrated using a P-10 concentrator (Amicon, Beverly, MA, U.S.A.) according to the manufacturer's instruction. The concentrated protein extracts were assayed for HMM activity and subjected to Western blot analysis as described by Wu and associates (1997).

\section{Quantitative analysis of pisatin.}

Approximately $100 \mathrm{mg}$ (fresh wt) of hairy roots was placed in $6 \mathrm{ml}$ of hexane contained in glass vials and gently shaken at room temperature overnight. The hexane was evaporated and the residue suspended in $25 \mathrm{ml}$ of $40 \%$ acetonitrile in water and subjected to high-performance liquid chromatography (HPLC) analysis. The extracted roots were dried at $80^{\circ} \mathrm{C}$ for 2 days to obtain dry weight measurements. HPLC analysis was carried out on an Econosphere C18 5U ( $5 \mu \mathrm{M}, 250$ by $4.6 \mathrm{~mm}$, Alltech Associates, Inc., Deerfield, IL, U.S.A.) column with a 40 to $95 \%$ acetonitrile/water gradient and a flow rate of 1 $\mathrm{ml} / \mathrm{min}$. The retention time for pisatin was $11 \mathrm{~min}$. The amount of pisatin was quantified by using a standard curve for pisatin.

\section{RNA analysis.}

Total RNA was prepared from hairy roots treated with $\mathrm{CuCl}_{2}$ and analyzed by Northern blotting as described by $\mathrm{Wu}$ and associates (1997). The probe used for the Northern analysis was antisense ${ }^{32} \mathrm{P}-\mathrm{RNA}$ transcribed using the $\mathrm{Hmm}$ gene in pHMM1 as a template. RNA transcription was carried out using a RNA transcription kit (Stratagene, La Jolla, CA, U.S.A.) according to the manufacturer's instructions.

\section{ACKNOWLEDGMENTS}

This research was supported by Department of Energy grant number DE-FG03-00ER15078. We thank G. Diczeno for help with the pisatin analysis by HPLC and helpful discussions, M. Hawes and F. Wen for teaching us the hairy root transformation technique, and C. Wasmann for editorial advice.

\section{LITERATURE CITED}

Akashi, T., Sawada, Y., Shimada, N., Sakurai, N., Aoki, T., and Ayabe, S. 2003. cDNA cloning and biochemical characterization of S-adenosyl-Lmethionine: 2,7,4'-trihydroxyisoflavanone 4'-O-methyltransferase, a critical enzyme of the legume isoflavonoid phytoalexin pathway. Plant Cell Physiol. 44:103-112.

Balaji, B., Poulin, M. J., Vierheilig, H., and Piche, Y. 1995. Responses of 
an arbuscular mycorrhizal fungus, Gigaspora margarita, to exudates and volatiles from the Ri T-DNA-transformed roots of nonmycorrhizal and mycorrhizal mutants of Pisum sativum L. sparkle. Exp. Mycol. 19:275-283

Banks, S. W., and Dewick, P. M. 1982. Biosynthesis of the 6a-hydroxypterocarpan phytoalexin pisatin in Pisum sativum. Phytochemistry 21:2235-2242.

Banks, S. W., and Dewick, P. M. 1983. Biosynthesis of pisatin: experiments with enantiomeric precursors. Phytochemistry 22:1591-1595.

Benhamou, N., and Garand, C. 2001. Cytological analysis of defenserelated mechanisms induced in pea root tissues in response to colonization by nonpathogenic Fusarium oxysporum Fo47. Phytopathology 91:730-740.

Boisson-Dernier, A., Chabaud, M., Garcia, F., Becard, G., Rosenberg, C., and Barker, D. G. 2001. Agrobacterium rhizogenes-transformed roots of Medicago truncatula for the study of nitrogen-fixing and endomycorrhizal symbiotic associations. Mol. Plant-Microbe Interact. 14:695700

Colliver, S. P., Morris, P., and Robbins, M. P. 1997. Differential modification of flavonoid and isoflavonoid biosynthesis with an antisense chalcone synthase construct in transgenic Lotus corniculatus. Plant Mol. Biol. 35:509-522.

Dewick, P. M. 1988. Isoflavonoids. Pages 125-209 in: The Flavonoids: Advances in Research Since 1980. J. B. Harborne, ed. Chapman and Hall, London.

DiCenzo, G. L. 1998. Elucidation of the late steps in pisatin biosynthesis. Ph.D. dissertation, University of Arizona, Tucson, U.S.A.

Fischer, D., Ebeanau-Jehle, C., and Grisebach, H. 1990. Phytoalexin synthesis in soybean: purification and characterization of NADPH: 2' hydroxydaidzein oxidoreductase from elicitor-challenged soybean cell cultures. Arch. Biochem. Biophys. 276:390-395.

Franck, A., Guilley, H., Jonard, G., Richards, K., and Hirth, L. 1980. Nucleotide sequence of cauliflower mosaic virus DNA. Cell 21:285-294.

Frisch, D. A., Harris-Haller, L. W., Yokubaitis, N. T., Thomas, T. L., Hardin, S. H., and Hall, T. C. 1995. Complete sequence of the binary vector Bin19. Plant Mol Biol. 27:405-409.

Gaffney, T., Friedrich, L., Vernooij, B., Negrotto, D., Nye, G., Uknes, S., Ward, E., Kessmann, H., and Ryals, J. 1993. Requirement of salicylicacid for the induction of systemic acquired-resistance. Science 261:754-756

Grebenok, R. J., Pierson, E., Lambert, G. M., Gong, F. C., Afonso, C. L., Haldeman-Cahill, R., Carrington, J. C., and Galbraith, D. W. 1997. Green-fluorescent protein fusions for efficient characterization of nuclear targeting. Plant J. 11:573-586.

Guo, L., Dixon, R. A., and Paiva, N. L. 1994. The 'perocarpan synthase' of alfalfa: association and co-induction of vestitone reductase and 7,2' dihydrox-4'-methoxy-isoflavanol (DMI) dehydrastase, the two final enzymes in medicarpin biosynthesis. FEBS (Fed. Eur. Biol. Soc.) Lett. 356:221-225

Han, Y., Liu, X., Benny, U., Kistler, H. C., and VanEtten, H. 2001. Genes determining pathogenicity to pea are clustered on a supernumerary chromosome in the fungal plant pathogen, Nectria haematococca. Plant J. 25:305-314

Heller, W., and Forkmann, G. 1994. Biosynthesis of flavonoids. Pages 499-535 in: The Flavonoids: Advances in Research Since 1986. J. B. Harborne, ed. Chapman and Hall, London.

Kistler, H. C. 1983. Phytoalexin metabolism and implication for phytoalexin tolerance and virulence in two pathogenic fungi. Ph.D. dissertation, Cornell University, Ithaca, NY, U.S.A

Kuc, J. 1995 Phytoalexins, stress metabolism, and disease resistance in plants. Annu. Rev. Phytopathol. 33:275-297.

Mackintosh, S. F., Matthews, D. E., and VanEtten, H. D. 1989. Two additional genes for pisatin demethylation and their relationship to the pathogenicity of Nectria haematococca on pea. Mol. Plant-Microbe Interact. 2:354-362.

Maloney, A. P., and VanEtten, H. D. 1994. A gene from the fungal plant pathogen Nectria haematococca that encodes the phytoalexin-detoxifying enzyme pisatin demethylase defines a new cytochrome P450 family. Mol. Gen. Genet. 243:506-514.

Mundodi, S. R., Watson, B. S, Lopez-Meyer M, and Paiva, N. L. 2001 Functional expression and subcellular localization of the Nectria haematococca Makl phytoalexin detoxification enzyme in transgenic tobacco. Plant Mol. Biol. 46:421-432.

Paiva, N., Edwards, R., Sun, Y., Hrazdina, G., and Dixon, R. 1991. Stress responses in alfalfa (Medicago sativa L.) 11. Molecular cloning and expression of alfalfa isoflavone reductase, a key enzyme of isoflavonoid phytoalexin biosynthesis. Plant Mol. Biol. 17:653-667.

Paiva, N. L., Sun, Y., Dixon, R. A., VanEtten, H. D., and Hrazdina, G. 1994. Molecular cloning of the isoflavone reductase from pea (Pisum sativum $\mathrm{L}$.): evidence for a $3 \mathrm{R}$-isoflavanone intermediate in (+)-pisatin biosynthesis. Arch. Biochem. Biophys. 312:501-510.

Preisig, C. L., Matthews, D. E., and VanEtten, H. D. 1989. Purification and characterization of $S$-adenosyl-L-methionine: 6a-hydroxymaackiain 3-O-methyltransferase from Pisum sativum. Plant Physiol.. 91:559566.

Preisig, C. L., VanEtten, H. D, and Moreau, R, A. 1991 Induction of 6ahydroxymaackiain 3-O-methyltransferase and phenylalanine ammonialyase mRNA translational activities during the biosynthesis of pisatin. Arch. Biochem. Biophys. 290:468-473.

Schlieper, D., Tiemann, K., and Barz, W. 1990. Stereospecificity of hydrogen transfer by fungal and plant NADPH: isoflavone oxidoreductases. Phytochemistry 29:1519-1524.

Sun, Y., Wu, Q., VanEtten, H. D., and Hrazdina, G. 1991. Stereoisomerism in plant disease resistance: Induction and isolation of the 7,2'-dihydroxy-4',5'-methylenedioxyisoflavone reductase, an enzyme introducing chirality during synthesis of isoflavanoid phytoalexins in pea (Pisum sativum L). Arch. Biochem. Biophys. 284:167-173.

Tegtmeier, K. J. 1981. Inheritance of phytoalexin tolerance, virulence on Pisum sativum $\mathrm{L}$ and other traits in the fungus Nectria haematococca MPVI. Ph.D. dissertation, Cornell University, Ithaca, NY.

Tegtmeier, K. J., and VanEtten, H. D. 1982. Genetic studies on selected traits of Nectria haematococca mating population VI. Phytopathology 72:604-607.

Thomma, B. P. H. J., Nelissen, I. Eggermont, K., and Broekaert, W. F. 1999. Deficiency in phytoalexin production causes enhanced susceptibility of Arabidopsis thaliana to the fungus Alternaria brassicicola. Plant J. 19:163-171.

vanEijsden, R. R., Diaz, C. L., dePater, B. S., and Kijne, J. W. 1995. Sugar-binding activity of pea (Pisum sativum) lectin is essential for heterologous infection of transgenic white clover hairy roots by Rhizobium leguminosarum biovar viciae. Plant Mol. Biol. 29:431-439.

VanEtten, H. D. 1978. Identification of additional habitats of Nectria haematococca mating population VI. Phytopathology 68:1552-1556.

VanEtten, H. D., Matthews, D. E., and Matthews, P. S. 1989. Phytoalexin detoxification: importance for pathogenicity and practical implications. Annu. Rev. Plant Pathol. 27:143-164.

Wasmann, C. C., and VanEtten, H. D. 1996. Transformation-mediated chromosome loss and disruption of a gene for pisatin demethylase decrease the virulence of Nectria haematococca on pea. Mol. PlantMicrobe Interact. 9:793-803.

Wen, F., Zhu, Y., and Hawes, M. C. 1999. Effect of pectinmethylesterase gene expression on pea root development. Plant Cell 11:1129-1140.

Wu, Q., Preisig, C. L., and VanEtten, H. D. 1997. Isolation of the cDNAs encoding (+) 6a-hydroxymaackiain 3- $O$-methyltransferase, the terminal step for the synthesis of the phytoalexin pisatin in Pisum sativum. Plant Mol. Biol. 35:551-560. 